\title{
Application of gravity model for trip analysis in transportation and traffic engineering for Owerri Metropolis Nigeria
}

\author{
Obi Lawrence E* \\ Department of Civil Engineering Imo State University, Owerri, Nigeria.
}

Global Journal of Engineering and Technology Advances, 2021, 07(01), 060-072

Publication history: Received on 09 January 2021; revised on 02 April 2021; accepted on 05 April 2021

Article DOI: https://doi.org/10.30574/gjeta.2021.7.1.0003

\begin{abstract}
The myriads of problems militating against the transportation system precipitated the conception of this research work. The survey design and empirical approaches were combined in the pursuance of this work. This work focused on the application of the gravity method in the trip analysis in Owerri metropolis. The research was able to estimate the number of trip interchanges among the various zones of the metropolis. The travel time from one zone to another zone within the study area was established. From this research, it was established that it would take 25 minutes and 50 minutes to travel from zone 5 to zone 2 and from zone 4 to zone 1 respectively. The number of trips from zone 3 to zone 4 was estimated to be 1146 trips and the number of trips generated and produced was put at 4119 trips per day. This research will help to curb the problem of dearth of data and aid the proper planning and management of the transportation system by engineers and other stakeholders.
\end{abstract}

Keywords: Gravity; Trips; Transportation; Generation; Attraction

\section{Introduction}

Transportation is the key to the economic development of every city. Transportation is the movement of people, goods and services from one point to another point. Transportation system that possesses all the necessary ingredients that make movements easy and affordable is considered as being ideal. The transportation system will normally feature multiple frameworks designed and created to make the movement of people, goods and services to run smoothly and help the traveler to achieve his targeted goals. This means that all bottlenecks that seem to be albatross towards the travelers' comfort, and mission should be eliminated. The viability of the transportation system should be the concern and objectives of the stakeholders and managers of the system. [1]. The processes in the transportation system should be tailored to yield high quality services, affordable pricing and also satisfaction of consumer demands. The viability of the system can only be guaranteed when the people, goods and services have unhindered mobility and accessibility. Transportation when put in a viable state enhances the quality of life. This can only be possible when the frontiers of the transportation are enlarged to embrace data analysis, new technologies and change in travel choices.

Transportation demand analysis is very critical in the sustainable development of the transportation system. It is the inevitability of data analysis that motivated the conception of this research. The research is focused in the trip generation and attraction analysis of travels made in the Owerri metropolis.

\subsection{Data analysis in transportation engineering}

There are big data in Transportation Engineering that require techniques to analyse and solve problems. The data analysis can be applied to problem solving that can precipitate long term improvements in transportation operations,

${ }^{*}$ Corresponding author: Obi Lawrence $\mathrm{E}$

Department of Civil Engineering Imo State University, Owerri.

Copyright (C) 2021 Author(s) retain the copyright of this article. This article is published under the terms of the Creative Commons Attribution Liscense 4.0. 
and planning which can extend to near term predictions in all ramifications of the transportation system. Data analysis will provide novel ideas about improved data injection, data curation, data archiving, data visualization and data security for better decision making. There are two major approaches to transportation data analysis and they include the qualitative analysis and quantitative analysis. The qualitative data analysis is an approach that is designed to answer questions on why, what or how, while the quantitative approach does its analysis based on measurement in terms of numerical information.

Interactive data visualization leverages human visual perception and cognition to improve the accuracy and effectiveness of data analysis. When integrated with data mining algorithms, data visualization systems combine human strengths with the computational power of machines. Most of the highways are developed based on the flow of traffic and the efficiency of generating revenue. After the entry of Public Private Partnership (PPP), traffic studies have been introduced to estimate the returns that can be generated through the particular highway [2].

Traffic and highway engineering work with historic data where a large set of data needs to be analyzed for purposes of understanding the existing scenarios and to develop forecasting models or prediction models. In Transportation engineering planning studies, a large set of data such as trips of people, modes used by people for travel, income of people, population data, vehicle population data, etc needs to be analyzed to understand the present pattern of travel and which needs to be forecasted for future to understand the demand for the future using, with which the infrastructure needs to be developed. In this case, there may be need for such of statistical methods such as regression, logit models, profit models, correlation analysis, curve filling, anova etc. Data analysis in transportation Engineering comes to rescue, being used to curb traffic congestion and enhance transport flow and management by aiding prediction and management of congestion. Sensors built on transport networks and fleet vehicles enable firms to collect data streams from local transport authorities.

\subsection{Transportation engineering}

Transportation engineering is the application of technology and scientific principles to the planning, functional design, operation and management of facilities for any model of transportation in order to provide for the safe, efficient, rapid, comfortable, convenient, economical and environmentally compatible movement of people, goods and services. The planning aspect of transportation engineering relates to elements of urban planning and involves technical forecasting decisions and political factors. Technical forecasting of passenger travel usually involves an urban transportation planning model, requiring the estimation of trip generation (number of purposeful trips) trip distribution (destination choice, where the traveler is going), mode choice (mode that is being taken) and route assignment (the streets, or routes that are being used). More sophisticated forecasting can include other aspects of traveler decision, including auto ownership, trip chaining, (the decision to link individual trip together in a tour) and the choice of residential or business location (known as land use forecasting). Passenger trips are the focus of transportation engineering because they often represent the peak of demand on any transportation system.

Facility planning and desire continue to constitute the core of transportation engineering and such other areas as operations, planning, logistics, network analysis, financing, and policy analysis are also of important consideration: Transportation engineering primarily involves planning, design, construction, maintenance and operation of transportation facilities. The facilities support air, highway, railway, pipeline, water and even space transportation. The design aspects of transportation engineering include the sizing of transportation facilities (how many lanes or how much capacity the facility has), determining the materials and thickness used in pavement designing and geometry (vertical and horizontal alignment) of the roadway or track [3].

Planning is prior to the taking of inventory of the area. The inventory is the data base. The inventory or database must include information on population, land use, economic activity, transportation facilities and services, travel patterns and volumes, laws and ordinances, regional financial resources, and community values and expectations. These inventories aid the engineer to create models to complete accurate forecasts of the future conditions of the system.

In the management and operations, traffic engineering takes the centre stage and it involves making sure the vehicles move smoothly on road or track. Other technique in this aspect includes signs, signals, markings and tolling. Modern technologies involve intelligent transportation system. Human factors include all aspects of transportation engineering, particularly driver-vehicle interface and user interface of roads signs, signals and workings [4]..

\subsection{Urban traffic modelling and analysis}

Urban traffic modeling and analysis is an integral part of the advanced traffic intelligent management technologies that has become a crucial sector of traffic management and control. Its main purpose is to predict congestion states of a 
specific urban transportation network and propose improvements in the traffic network. Historical and recent data of a traffic network talks about its density and flow which can be used for a model of the transport network infrastructure and algorithms referring to both spatial and temporal dimensions. Its final objective is to provide a better optimization of the traffic infrastructure such as traffic lights. Those optimizations will lead to the decrease of travel times, pollution and fuel consumption [4]. The uses of intelligent transportation systems are very important for use in urban areas because they are mainly densely populated both in humans and vehicles. They provide the possibility to manage and better analyze transport network impact of external factors within a short term vision with daily fluctuating density of the transportation network. For a long term vision, it looks at the changes in population density, increase in motorization, urbanization, population growth, etc.

Efforts have been made into traffic analysis by collecting traffic data from different sources, modeling traffic flow, and network and developing algorithms to either predict traffic state in a short term future.

\subsection{Trip analysis}

Urban planners and transport engineers have long been developing different methods and models to forecast travel demand in urban areas. Travel demand forecasting is the element for designing transportation facilities and developing urban planning policies and regulations. One of the most common approaches used to model demand is the four step travel demand modeling process. The very first step of four-step travel demand modeling is forecasting the trip generations. Trip generation aims at the estimation of the total number of trips generated from a zone and attracted to a zone [5]. Accordingly, trip attraction identifies the number of trips attracted by land use activities in a traffic analysis zone (TAZ) and trip production identifies the number of trips produced by household in a Trip Analysis Zone. Studies on travel demand have discovered that trip attraction has strong co-relation with land use types and its activities such as land use distribution, floor area, number of employees and number of shops, number of schools and school enrolment rate, number of employees in the commercial node, number of offices in the commercial node, number of employment opportunities, gross floor area, number of stores in the shopping area, number of schools and volume of retail sale, number of parking lots.

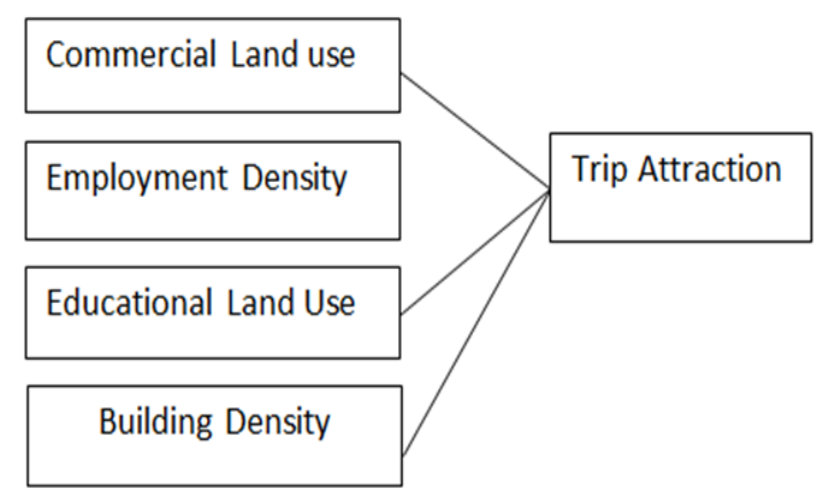

Figure 1 Factors that Contribute to Volume of Trip Attraction

Researchers have observed that executing of land use-based trip attraction models are severely constrained especially in developing countries due to lack of updated land use data and trip rates. Studies on centrality and building revealed that there is a correlation between centrality and building and street centrality and characteristics of building environment such as density of commercial land uses, distribution of land values, distribution of employment density, distribution of linking density and distribution of spatial form. The relationship is shown in figure 2 . 


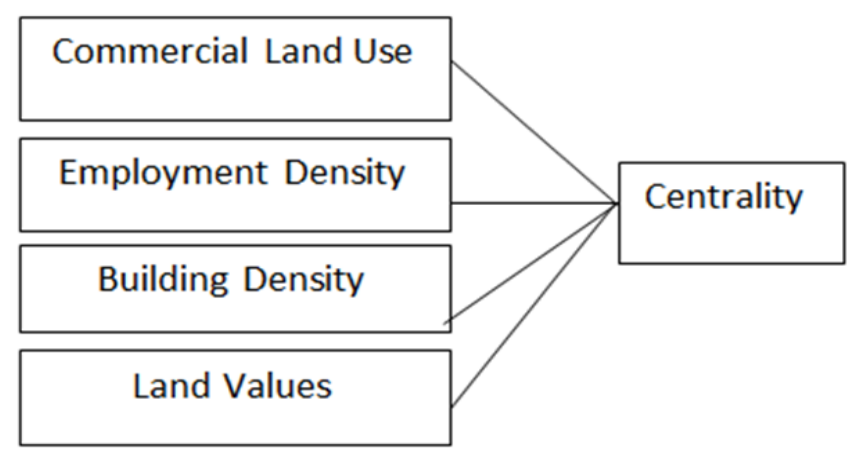

Figure 2 Relationship between Characteristics of Building Environment and Street Centrality

There is a relationship between street centrality and trip attraction. It can be observed that the centrality of the road network can affect the trip attraction.

\subsection{Trip generation}

This is the first step in the conventional four-step transportation forecasting process (which is followed by trip distribution, mode choice and route assignment), widely used for forecasting travel demands. It predicts the number of trips originating in or destined for a particular traffic analysis zone. Typically, trip generation analysis focuses on residents and residential trip generation and it is thought of as a function of the social and economic attributes of households. At the level of traffic analysis zone, residential; land uses produce or generate trips. Traffic analysis zones are also destinations of trips, and trip attractors. The analyses of attractors are based on non-residential land uses [6].

A forecasting activity, such as one based on concept of economic base analysis, provides aggregate measures of population and activity growth. Land use forecasting distributes forecast changes in activities in a disaggregate- spatial manner among zones. The next step in transportation planning process addresses the question of the frequency of origins and destinations of trips in each zone.

Different production and attraction models are used for each trip purpose. Special generation models are used to estimate non-home-based, taxi and external trips. Overtime the understanding came that considerable predictive power and accuracy can be gained by disaggregate analysis of influential variables. This means that the models use factors describing individual sample unit (e.g persons, households or workplaces) rather than an average value of each factor for each analysis zone. The result is trip generation models with trip rates for sample units waving specific characteristics such as households, of one, two or more family members, owning one or two or more vehicles.

\subsection{Trip generation models}

The trip generation models aims at predicting the total number of trips generated and attracted to each trip analysis zone (TAP). Transport planning agencies need to collect the survey travel data, land use data, socio economic data determining the trip generation model. Trip generation models require such data as population, household, employment, vehicle ownership and income. Current information on these variables can be obtained from household surveys or census reports. Future information can be obtained through projection. Household based schemes are more common in current practice even though they require an addition process of obtaining zone level totals [6].

There are two kinds of trip generation models namely production models and attraction models. Trip production models estimate the number of home-based trips to-and-from the zones where trip makers reside. Trip attraction models estimate the number of home based trips to-and -from each zone at the non-home end of the trip.

\subsection{Hypermobility travel}

Hypermobile travelers are highly mobile individuals who take frequent trips often over great distances. They account for a large share of the overall kilometers travelled especially by air. These people contribute significantly to the overall amount of airmiles flown within a given society. Although, concerns over hypermobility apply to several modes of transport, the environmental effect of aviation and especially its greenhouse emissions have brought particular focus on flying. Among the reasons for this focus is that these emissions, because they are made at high altitude, have a climate impact that is commonly estimated to be 2.7 higher than the same emissions made at the ground level. 
It is true that the amount of time people have spent in motion has remained constant since 1950, the shift from feet and bicycles to cars and planes has increased the speed of travel fivefold. This results to the twin effects of wider and shallower regions of social activity around each person (further exacerbated by electronic communication which can be seen as a form of virtual mobility), and a degradation of the social and physical environment brought about by the high speed. [7]

The changes are brought about locally due to the use of cars and motorways and internationally by aeroplanes. Some of the social threats of hypermobility are more polarization between the rich and poor, and reduced health and fitness. Widespread internet use is seen as a contributory factor towards hypermobility due to the increased ease with which it enables travel to be desired and organized. To the extent that internet stimulates travel; it represents a lost opportunity to reduce overall emissions because online communication is a straightforward substitute for physical travel.

The term hypermobility started in 1980 concerning the flow of capital and in the 1990s it was extended to travels. These models are based on the trip rates for individual sample households having those particular discrete characteristics. Trip generation models are intended to prognosticate the total number of trips produced or attracted by a zone. Trips are two way excursions originating at the trip makers home. The number of trips attracted to the zone is assumed to depend on the characteristics of its economic activities. In most cases, trip generation models are of a general form, summarized in a linear function of the form. $P_{i}=\sum a_{j} z_{i j}$ Where a_i are coefficients to be determined from regression analysis.

\subsection{Transport demand analysis}

Transport demand analysis plays such roles in transportation engineering management and planning. The roles include

- Understanding the long range social and environmental implications of decisions about transportation engineering

- Understanding the short range predictions of passenger or vehicular flows that are used by designers to size facilities such as park sizes, number of stops etc.

- Develop operating and control strategies

- Assess the impact of land development and transportation projects

The basic target of transportation demand analysis is to describe travels meaningfully, to explain travel behavior and thus helps to make prognostication of demand for various types of transportation services [7].

\subsection{Travel behaviour}

Trip is the smallest unit of travel behavior. Trip is defined in terms of origins, destinations, purposes, times of occurrence, travel modes and routes. Trip chains or trip patterns are defined as sets of trips beginning at the travelers home and proceeding to several destinations in sequence before returning to the starting point. Transportation demand analysis attempts to explain travel behaviour in primary economic terms.

In economics, the theory of consumer behavior is based on the concept of utility which is expressed in mathematical terms by means of a utility function. Reduced to its simpliest simplest form, the utility function expresses the consumers indifference between various alternative choices or attributes of these choices. The utility function $U=f(x, y)$. This function implies that the individual is indifferent in a choice between $\mathrm{x}$ and $\mathrm{y}$ for all values that produced U. It therefore means that the individual will prefer all combinations $U_{-} 1$ of $X$ and $y$ to all combinations of $U_{-} 2$ of $x$ and $y$, if $U_{-} \_1=f \_1$ $(\mathrm{x}, \mathrm{y})>\mathrm{U} \_2=\mathrm{f} \_2(\mathrm{x}, \mathrm{y})$.

In a classical form the utility function expresses the relative amounts of various goods a consumer will choose given a budget constraints that limits the total number of goods achievable. In the analysis of travel choices, it applies to mutually exclusive alternatives since it is impossible to make two trips at the same time. The idea therefore is that an individual will make a travel if the utility of travelling exceeds that of not travelling. Consequently, in a maze of alternatives to travel (make a trip) the one with the greatest utility becomes the choice.

The utility of any particular trip is partially dependent on the activity or profit it makes possible and the way the activity is valued by the traveler individual. Trips involve costs of making the trip and these are called disutilities. The time cost of a trip is broken down into two namely time spent riding and the time spent walking or waiting for a service. 


\subsection{Travel demand model}

It is true that utility theory provides a critical basis for mathematical modeling of travel behavior but it is only a starting point. Utility model is an abstract description of individual behavior. Travel demand models must predict group behavior. Most demand models structure trip choices into a sort of sequence.

The most common approach to demand modeling is to structure the choice sequence by stratifying trips by purpose and time of the day. Trip purpose may be put into work or non-work trips. A more elaborate scheme can include work, shopping, personal business, and educational, religious, social and recreational trips. Such schemes are based on frequency, regularity and time of the day the different trips are made. Time of the day stratification is between worktrip peaks and off-trip peak periods. Trips are also classified on whether they take place on weekdays or weekends [8]

For each combination, trip purpose and time of the day separate models are developed for the number of trips mode (trip generation), their origins and destination (trip distribution), the mode used (mode choice) and the route followed (trip assignment). Such models require information about socio economic conditions and land use and where they are intended to predict travel demand very far in future.

The transportation demand modeling sequence is illustrated below;

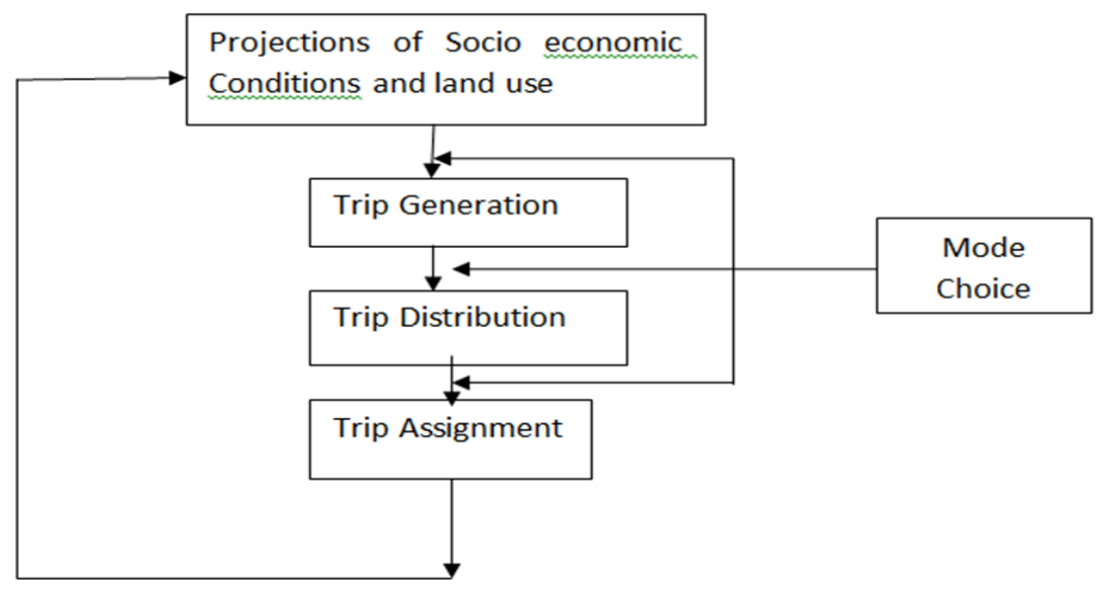

Figure 3 The transportation demand model

\subsection{Trip distribution models}

Trip distribution model is one that estimates the number of trips that occur between each origin zone and each destination zone. It uses the prognosticated number of trips originating in each origin zone (rip production model) and the prognosticated number of trips ending in each zone (trip attraction model) [8].

Trip distribution is the second component in the traditional four-step transportation forecasting model. This step marks the trip markers origins and destinations to develop a trip table. A trip table is a matrix that depicts the number of trips going from each origin to each destination.

The distribution models are meant to predict zone to zone trip interchanges. There are several types of trip distribution models namely Frator Growth, Factor model, Intervening Opportunities Model, Competing Opportunity Model and Gravity model. The Gravity Model is the most popular and more widely applied [9].

\section{Methodology}

The method employed is the research survey design method and the application of the gravity method.

\subsection{Area of study}

The study area is Owerri Imo State Nigeria with area capacity of 58km2 and it has a population of 127,213 according to 2006 census. The map of the study area is shown in figure 4; 


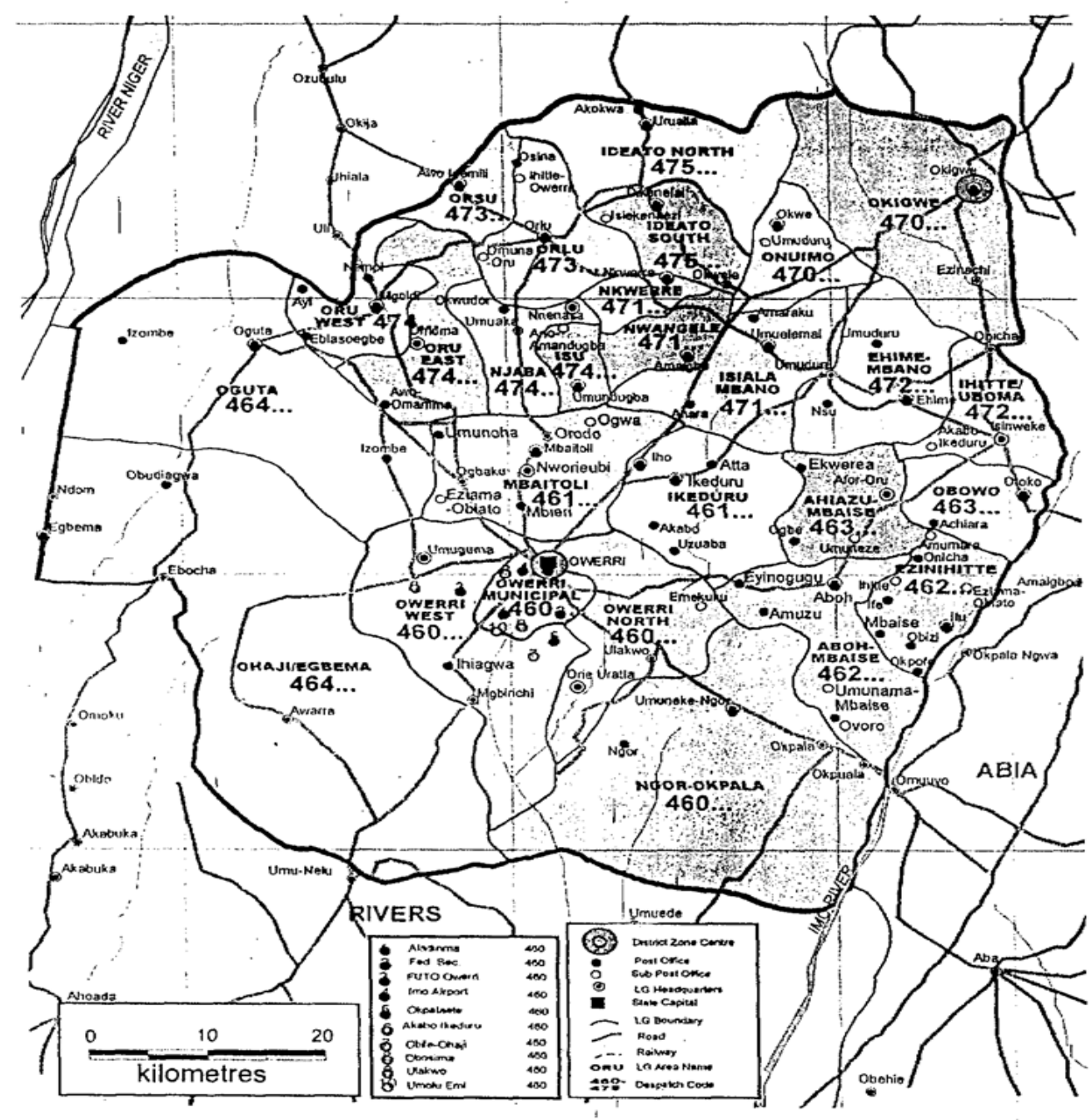

Figure 4 Map of Owerri

The study area was delineated into zones.

\subsection{Data collection}

Data were collected in the study area according to the designated zones. The data collected included number of trips from one zone to another, trip attractions to the zones, trip generations in each zone, predictive factors for trip production, predictive factors for attraction travel time from one zone to another, and the impedance of travel was determined.

\subsection{Gravity model}

The gravity model is a trip distribution model and it is the most popular method employed in traffic and transportation engineering analysis due to its inherent advantages. The gravity model has its formula as stated as given thus;

$$
T_{i j}=\frac{P_{i}\left(A_{j} F_{i j}\right)}{\sum_{j}\left(A_{j} F_{i j}\right)}
$$

Alternatively, the above formular can also be stated as 


$$
T_{i j}=\frac{A_{j}\left(P_{i} F_{i j}\right)}{\sum_{j}\left(P_{i} F_{i j}\right)}
$$

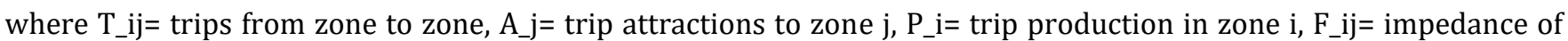
travel from zone $\mathrm{i}$ to zone $\mathrm{j}$. The impedance travel from zone $\mathrm{i}$ to zone $\mathrm{j}$ is usually some function of travel time or generalized cost of travel between two zones. The impedance, F_ij is given thus,

$$
F_{i j}=C_{i j}^{-a}
$$

Where $\mathrm{C}_{-} \mathrm{ij}=$ generalised cost function from zone $\mathrm{i}$ to zone $\mathrm{j}$ and $\mathrm{a}=$ model parameter $=1.90$

\subsection{Trip generation model}

Trip generation model helps to predict total number of trips produced or attracted by an area. Trip generation models are of the general form;

$$
\begin{aligned}
& P_{i}=f\left(Z_{1}, Z_{2}, Z_{3, \ldots \ldots}\right) \\
& A_{i}=f\left(\lambda_{1}, \lambda_{2}, \lambda_{3}, \ldots .\right)
\end{aligned}
$$

The common form of a trip generation is a linear function of the form

$$
P_{i}=\sum a_{j} z_{i j}
$$

Where $a_{-} j=$ coefficient

\section{Results}

Data were collected from the field on the respective zones and the information on trip interchanges among the zones was also obtained. The data collected are arranged and presented as shown on Table 1

Table 1 Trip Interchanges Among the zones in the study Area (from zone 1 to other zones)

\begin{tabular}{|l|l|l|l|}
\hline Zone & Travel Time to zone 1 (min) & Productions & Attractions \\
\hline 1 & - & 5,000 & 3,000 \\
\hline 2 & 15 & 2,000 & 5,000 \\
\hline 3 & 25 & 4,500 & 3,200 \\
\hline 4 & 20 & 7,000 & 4,500 \\
\hline 5 & 35 & 3,000 & 6,000 \\
\hline
\end{tabular}

The trip interchanges from zone 2 to other zones were also collected and presented in Table 2

Table 2 Trip interchanges from Zone 2 to other Zones.

\begin{tabular}{|l|l|l|l|}
\hline Zone & Travel Time to zone 2 (min) & Productions & Attractions \\
\hline 1 & 15 & 3,000 & 6,000 \\
\hline 2 & - & 8,000 & 2,000 \\
\hline 3 & 30 & 4,000 & 8,000 \\
\hline 4 & 20 & 6,000 & 7,000 \\
\hline 5 & 25 & 9,000 & 5,000 \\
\hline
\end{tabular}


The trip interchanges from zone 3 to other zones are presented on Table 3

Table 3 Trip interchanges from zone 3 to other Zones.

\begin{tabular}{|c|c|c|c|}
\hline Zone & $\begin{array}{lcc}\text { Travel } & \text { Time } & \text { to } \\
\text { Zone } 3 & \text { (min) }\end{array}$ & Productions & Attractions \\
\hline 1 & 25 & 10,000 & 6,500 \\
\hline 2 & 30 & 4,000 & 2,000 \\
\hline 3 & - & 6,000 & 5,000 \\
\hline 4 & 40 & 7,000 & 8,500 \\
\hline 5 & 20 & 3,000 & 4,500 \\
\hline
\end{tabular}

The trip interchanges from zone 4 to other zones are shown on Table 4,

Table 4 Trip Interchanges from Zone 4 to other Zones.

\begin{tabular}{|l|l|l|l|}
\hline Zones & $\begin{array}{l}\text { Travel Time to Zone } \\
\mathbf{4}(\mathbf{m i n})\end{array}$ & Productions & Attractions \\
\hline 1 & 50 & 4,000 & 5,000 \\
\hline 2 & 35 & 5,000 & 7,000 \\
\hline 3 & 40 & 17,000 & 9,000 \\
\hline 4 & - & 9,000 & 6,000 \\
\hline 5 & 30 & 6,000 & 8,000 \\
\hline
\end{tabular}

The trip interchanges from 5 to other zones as shown on Table 5;

Table 5 Trip interchanges from Zone 5 to other Zones

\begin{tabular}{|l|l|l|l|}
\hline Zone & $\begin{array}{l}\text { Travel Time to Zone } \\
\mathbf{5}(\mathbf{m i n})\end{array}$ & Productions & Attractions \\
\hline 1 & 25 & 4,500 & 3,500 \\
\hline 2 & 40 & 6,000 & 8,500 \\
\hline 3 & 50 & 5,000 & 9,500 \\
\hline 4 & 30 & 3,000 & 4,500 \\
\hline 5 & - & 2,500 & 8,000 \\
\hline
\end{tabular}

Data were also collected on the households and vehicles and the results were arranged.The trip rates (trips per Household per Day) were presented on Table 6; 
Table 6 Trip Rates (Trips Per Household Per Day).

\begin{tabular}{|l|ccc|}
\hline \multirow{2}{*}{$\begin{array}{l}\text { Persons Per } \\
\text { Household }\end{array}$} & \multicolumn{4}{|c|}{ Vehicles Available Per Household } \\
\cline { 2 - 4 } & 0 & 1 & $\geq 2$ \\
\hline 1 & 1020 & 1910 & 2120 \\
\hline 2 & 2140 & 3160 & 3610 \\
\hline 3 & 2610 & 3710 & 3830 \\
\hline$\geq 4$ & 3970 & 5130 & 5650 \\
\hline
\end{tabular}

Data collected on the fraction of Household size and Vehicle Availability are shown on Table 7;

Table 7 Fraction of Household Size and Vehicle Availability.

\begin{tabular}{|l|ccc|}
\hline $\begin{array}{l}\text { Persons Per } \\
\text { Household }\end{array}$ & \multicolumn{3}{|c|}{ Vehicles Available Per Household } \\
\cline { 2 - 4 } & 0 & 1 & $\geq 2$ \\
\hline 1 & 0.06 & 0.31 & 0.03 \\
\hline 2 & 0.05 & 0.17 & 0.15 \\
\hline 3 & 0.07 & 0.11 & 0.18 \\
\hline$\geq 4$ & 0.02 & 0.09 & 0.07 \\
\hline
\end{tabular}

From the survey carried out in the entire study area and the data collected based on the household size, as reflected on the table 6 and 7, the numbers of trips in the study area can be estimated using the trip generation model. The model which has a form $P_{i}=\sum \sum b_{i} K_{i j}$ can be applied in this estimation thus;

$$
\begin{aligned}
P=1020 *(0.06) & +1910(0.31)+2120(0.03)+2120(0.03)+2140(0.05)+3160(0.17)+361(0.15)+2610(0.07) \\
+ & 3710(0.11)+3830(0.18)+3970(0.02)+5130(0.09)+5650(0.07) \\
= & 61.2+591.2+63.6+107+537.2+541.5+182.7+408.1+689.4+79.4+461.7+395.5 \\
= & 4119 \text { trips per day }
\end{aligned}
$$

\begin{tabular}{|c|c|c|c|c|c|}
\hline Zone & $A_{j} C_{i j}(\min )$ & & $\frac{{ }^{j} / C_{i j}^{a}}{{ }_{{ }_{j}} / C_{i j}^{a}} T_{i j}$ & $\frac{\left.A_{j} / C_{i j}^{a}\right)}{\left.A_{j} / C_{i j}^{a}\right)}$ & \\
\hline 1 & 3000 & 0 & & & \\
\hline 2 & 5000 & 25 & 29.13 & 0.499 & 2495 \\
\hline 3 & 3200 & 25 & 7.06 & 0.121 & 605 \\
\hline 4 & 4500 & 20 & 15.18 & 0.260 & 1300 \\
\hline 5 & 6000 & 35 & 6.99 & 0.120 & 600 \\
\hline$\Sigma$ & & & 58.36 & 1.00 & \\
\hline
\end{tabular}

With the primary data on Table 1, a table that will enable us calculate the trips from zone 1 to other zones is shown on Table 8;

Table 8 Calculation Table for Trips from Zone 1 to other Zones.

Following the Table 2, a calculation table is developed for the determination of trips from Zone 2 to other zones and it is presented on Table 9 as shown 
Table 9 Calculation Table for Trips from Zone 2 to other Zones.

\begin{tabular}{|l|ccccc|}
\hline Zone & $A_{j} C_{i j}(\mathrm{~min})$ & \multicolumn{5}{c|}{$A_{j} / C_{i j}^{a} \frac{A_{j} / C_{i j}^{a}}{\sum A_{j} / C_{i j}^{a}} T_{i j}=\frac{P_{2}\left(A_{j} / C_{i j}^{a}\right)}{\sum\left(A_{j} / C_{i j}^{a}\right)}$} \\
\hline 1 & 6000 & 15 & 34.961 & 0.426 & 3408 \\
\hline 2 & 2000 & - & - & - & - \\
\hline 3 & 8000 & 30 & 12.490 & 0.152 & 1216 \\
\hline 4 & 7000 & 20 & 23.612 & 0.288 & 2304 \\
\hline 5 & 5000 & 25 & 11.038 & 0.134 & 1072 \\
\hline$\Sigma$ & & & 82.101 & 1.000 & \\
\hline
\end{tabular}

In like manner, the calculation table for trips from zone 3 to other zones is shown in Table 10;

Table 10 Calculation Table for Trips from Zone 3 to other Zones.

\begin{tabular}{|l|ccccc|}
\hline Zone & $A_{j} C_{i j}$ (min) & & $A_{j} / C_{i j}^{a} \frac{A_{j} / C_{i j}^{a}}{\sum A_{j} / C_{i j}^{a}} T_{i j}=\frac{P_{\mathbf{3}}\left(A_{j} / C_{i j}^{a}\right)}{\sum\left(A_{j} / C_{i j}^{a}\right)}$ & \\
\hline 1 & 6500 & 25 & 14.349 & 0.356 & 2136 \\
\hline 2 & 2000 & 30 & 3.122 & 0.077 & 462 \\
\hline 3 & 5000 & - & - & - & - \\
\hline 4 & 8500 & 40 & 7.683 & 0.191 & 1146 \\
\hline 5 & 4500 & 20 & 15.179 & 0.376 & 2256 \\
\hline$\Sigma$ & & & 40.333 & 1.000 & \\
\hline
\end{tabular}

The calculation table for the determination of trips from Zone 4 to other zones is shown on Table 11;

Table 11 Calculations Table for Trips from Zone 4 to other Zones.

\begin{tabular}{|c|c|c|c|c|c|}
\hline Zone & $A_{j} C_{i j}(\mathrm{n}$ & & $\frac{A_{j} / C_{i j}^{a}}{\sum A_{j} / C_{i j}^{a}} T$ & $\frac{\boldsymbol{P}_{\mathbf{4}}\left(\boldsymbol{A}_{\boldsymbol{j}} / \boldsymbol{C}_{\boldsymbol{i} \boldsymbol{j}}^{\boldsymbol{a}}\right)}{\sum\left(\boldsymbol{A}_{\boldsymbol{j}} / \boldsymbol{C}_{\boldsymbol{i} \boldsymbol{j}}^{\boldsymbol{a}}\right)}$ & \\
\hline 1 & 5000 & 50 & 2.957 & 0.093 & 837 \\
\hline 2 & 7000 & 35 & 8.154 & 0.257 & 2313 \\
\hline 3 & 9000 & 40 & 8.134 & 0.256 & 2304 \\
\hline 4 & 6000 & - & - & - & - \\
\hline 5 & 8000 & 30 & 12.490 & 0.390 & 3546 \\
\hline$\Sigma$ & 31.715 & & & & \\
\hline
\end{tabular}

From Table 5, a calculation table is derived as shown on Table 12; 
Table 12 Calculation Table for Trips Zone 5 to other Zones

\begin{tabular}{|c|c|c|c|c|c|}
\hline \multirow{2}{*}{$\begin{array}{l}\text { Zone } \\
1\end{array}$} & \multicolumn{5}{|c|}{$A_{j} C_{i j}(\min ) \quad A_{j} / C_{i j}^{a} \frac{A_{j} / C_{i j}^{a}}{\sum A_{j} / C_{i j}^{a}} T_{i j}=\frac{P_{5}\left(A_{j} / C_{i j}^{a}\right)}{\sum\left(A_{j} / C_{i j}^{a}\right)}$} \\
\hline & 3500 & 25 & 7.726 & 0.231 & 578 \\
\hline 2 & 8500 & 40 & 7.683 & 0.229 & 573 \\
\hline 3 & 9500 & 50 & 5.619 & 0.168 & 420 \\
\hline 4 & 4500 & 30 & 12.490 & 0.373 & 933 \\
\hline 5 & 8000 & - & - & - & - \\
\hline$\Sigma$ & & & 33.518 & 1.000 & \\
\hline
\end{tabular}

\section{Discussion}

The information contained on Tables 3.1 to 3.5 showed the primary data collected from the field and it included travel time from one zone to another, the trips produced or generated at the zone and the number of trips attracted by the zone in question. It can be observed from the table 3.1 that the time taken to travel from Zone 1 to Zone 2 was $15 \mathrm{minutes}$ and on table 3.2, it was also noticed that the time taken to travel from Zone 2 to Zone 1 stood at 15minutes. This goes a long way to buttress the consistency and accuracy of the field data collection.

The gravity model was actually employed to estimate the distribution of trips in the zones in terms of the interchanges of trips. The economic status of a zone is a critical factor that attracts travelers to the zone. Apart from that, sports, tourism, recreational facilities, religious centre and educational institutions play a major role in attracting trips to an area. The distribution of trips from zone to zone was illustrated on Table 3.8 to 3.12. For instance on Table 3.10, the trip distribution from zone 3 to other zones was fully estimated thus number of trips from zone 3 to zone 1, (T_31)=2136 trips, from zone 3 to zone 2, (T_32 )=462 trips, from zone 3 to zone 4, (T_34 )=1146 trips and from zone 3 to zone 5 (T_35 )=2256 trips.

The generation model was used to estimate the number of trips produced or generated within the area. From the data collected on household size and vehicles availability, a total of 4119 trips per day from a particular zone were estimated to be produced.

\section{Conclusion}

Data collection and analysis are very paramount in highway and transportation engineering. Transportation engineering has much to do with regards to raising the standards and quality of operations of the movement of people. This work has added value to the transportation system by developing data which can assist stakeholders especially engineers on how the best to carry out their duties. The data generated are critical to the proper management and planning in transportation and highway engineering. The determination number of trips from one sub-area to another sub area within the study area serves as a guide to the operators in the scheduling of personnel, vehicles and even in the allocation of resources to their various routes within the study area. This by extension will expose the roads that are more frequently plied and the knowledge of this will help the engineers to identify critical roads within the area.

\section{Compliance with ethical standards}

\section{Acknowledgment}

It is my pleasure to thank my students who motivated me into this research to enable them have a firm grip of the time they will spend in shuttling between the various zones within the Owerri Metropolis.. This, they suggested will aid them to be in the lecture at the appropriate time. I further thank them for helping me to monitor the timing and enumerations at the research points. I wish to appreciate my wife Law-Obi Fidelia and all my children for providing the enabling environment. My colleagues at the Department of Civil Engineering Imo State University Owerri Nigeria are appreciated for their support. 


\section{References}

[1] Daniel S, Alexandra K, Qiang B. Driver bEhaviour, Highway Capacity and Transporattion Resilience Journal of Traffic \& Transportation Engineering. 2017.

[2] Dung TN, Yoshitaka K. Traffic Congestion and Impact on the Environment in Vietnam, Journal of Civil and Environmental Engineering. 2018.

[3] Amila Jayasingbe, Kaseulsri R. Application for Developing Countries: Estimate trip attraction in Urban zones based on centrality, Journal of Traffic and Transportation Engineering (English Edition). 2017.

[4] Obi LE. Achieving Transportation System Sustainability with ICT on the Driving Seat, International Journal of Scientific Innovations Medina New Road, Ghana. 2020;8(1).

[5] Samear HH, Armin SAS. Modeling and Detecting Traffic Dynamics, Granular, Pedestrian and Vehicular Flow, Journal of Traffic and Transportation Engineering (English Ed). 2020.

[6] Shantanu D, David L. A queuing and Statistical Analysis of Freeway Bottleneck Formation, Journal of Transportation Engineering

[7] en.m.wikipedia. transport.2004.

[8] Adel WS, Anuji S. Big Data Analysis, Journal of Big Data Analytics in Transportation. 2020.

[9] Peter TM. Turning Movement Estimation, Journal of Transportation Eng. 1995. 